\title{
High temperature calibration of calcite clumped isotopes: When theory meets experimentation
}

\author{
JOSUÉ J. JAUTZY ${ }^{1}$, MARINE M. SAVARD ${ }^{1}$, RYAN S. \\ DHILLON $^{2}$, STEFANO M. BERNASCONI ${ }^{3}$, ANNA \\ SMIRNOFF $^{1}$ \\ ${ }^{1}$ Geological Survey of Canada, Natural Resources Canada, \\ Québec, Canada \\ ${ }^{2}$ Queen's University, Geological Sciences and Geological \\ Engineering, Kingston, Canada \\ ${ }^{3}$ ETH-Zürich, Department of Earth Sciences, Zürich, \\ Switzerland \\ *josue.jautzy@canada.ca
}

Measurements of clumped isotopes $\left(\Delta_{47}\right)$ excess abundances in carbonates is becoming a widespread isotopic geothermometer which also casts the precipitating fluid $\delta^{18} \mathrm{O}$ composition. While $\Delta_{47}$-temperature $(\mathrm{T})$ relationship discrepancies between laboratories have been considerably reduced over the past 10 years, theoretical and experimental calibrations have still not been reconciled. Moreover, a lack of high T measures has weakened the application of the method to high temperature calcite contexts. Here, we present a calcite $\Delta_{47}-\mathrm{T}$ calibration between 5 and $750^{\circ} \mathrm{C}$, using synthetically precipitated and heated calcites, to extend the calcite $\Delta_{47}-\mathrm{T}$ calibration at high temperature. By showing strong similarities between the calibration proposed here, theoretical and all published T-calibrations made using a fullcarbonate referencing scheme, this study: (1) provides a calibration allowing more precise application in high $\mathrm{T}$ geological contexts, (2) further supports the improvement of interlaboratory comparison by using carbonate standards, and (3) reconciles empirical Tcalibrations with theory. 